remained three years, at the end of which time he removed to the site of the present capital, Reikjavik ("Reeky Bay"), where superstition apparently determined him to remain, notwithstanding the remonstrances of his servants, who had seen many more inviting spots along the coast. Meantime Leif, or Thorleif as he was now called, from a big sword he brought back with him from Ireland, had built his house"at Thorleifshöfde, where, in the first spring after his arrival, he began to cultivate the ground. Having only one ox, however, the story goes, he compelled his Irish slaves to draw the plough; they thereon rebelled and murdered their master, they themselves being in turn pursued and nearly all killed by Ingolf, who then appropriated all the country between the river Olousa and Hval Fjord. The oppressions of Harold the Fair-haired soon sent many of the best of Norway's sons to become settlers in the new colony, and thus it was that Iceland was peopled, not by the scum of the mother country, as is too often the case, but by the best blood of old Norway. This influx of colonists continued for sixty years, when, the causes of emigration from Norway having ceased, and the best ground in Iceland having been fully occupied, immigration gradually came to an end.

From the first the colonists seem to have set themselves to make the best of their not very promising surroundings, and ere long to have settled down into a comparatively peaceful and contented community. One Ulfleet is said to have compiled a code of laws, and instituted the "Althing," or National Assembly, in 928, when for the first time it met at Thingvalla. Among other enactments pauperism was suppressed as a crime by the severest laws, one of which was intended effectually to prevent the procreation of a pauper class in a country where it was only by dint of the hardest labour that the sea and the land could be made to yield enough for all. The colonists were converted to Christianity about the year 1,000 ; in $126 \mathrm{I}$, after many internal contests, the whole island swore allegiance to the Norwegian king, but about 1387 it was transferred to Denmark, attached. to which kingdom it has ever since remained. The King of Denmark is now on the island ---an event of the rarest occurrence-and, as we have said, is to grant to his Icelandic subjects a new and liberal constitution; we believe he is accompanied by Prof. Steenstrup.

This, deprived of detail and of much that is doubtful - though the Icelanders have less of the legendary in their early history than most other old countries -is the story of the colonisation of Iceland a thousand years ago. We have not space to enter into further detail concerning the physical aspect of the island, the character and customs of the people, their wonderful literature in all departments of intellectual activity, their discovery of and long intercourse with Greenland and North America. Greenland was seen by an Icelander, Gunnbjorn, so early as 877 , and for centuries after some rocks between Iceland and Greenland were known as "Gunnbjorn's Skerries." Erik Rauda ("the Red ") first visited Greenland in 983 ; three years afterwards he planted a colony on the south-west coast. We understand that a deputation from America is attending the millenary fêtes now being held in Iceland, and that some of the American scientific societies have shown their good- will by sending valuable presents of books, \&c. This is right and becoming on the part of the Americans, for, as we have just indicated, the Icelanders were the first European colonists of America, and had regular intercourse with the western continent for about 300 years ; and it is curious to conjecture what might have been the history of that continent had the Norse attempts at colonisation not proved abortive. It is by no means improbable that Columbus himself, when he made that northern voyage in 1467 , "a hundred leagues beyond Thule," may have heard some fragmentary traditions of the Greenland colony which he may have treasured in his heart as a confirmation of the idea which was subsequently to bear so rich fruit.

The history ofthis old Norse colony proves that the people have great capacity for work, and we again hope that this celebration of the courage and dauntless energy of their forefathers will be the means of rousing them to renewed activity, which will be beneficial both to themselves and to the world at large, which has increasing need of all the really good working power it can command.

\section{RECENT RESEARCHES IN PHOTOGRAPHY}

A SUBSTANTIAL contribution has been recently A made to our knowledge of the action of light upon silver salts-a contribution which we cannot but consider as of the highest importance to photography, both as a science and as an art.

In the autumn of last year Dr. Herman Vogel announced ${ }^{*}$ as the result of some experiments that he had been making, that "we are in a position to render bromide of silver sensitive for any colour we choose-that is to say, to heighten for particular colours the sensibility it was originally endowed with." This discovery is such a decided advance that it will be interesting to trace it from the beginning. Dr. Vogel, in the first instance, found to his astonishment that some dry bromide plates prepared by Col. Stuart Wortley in this country were more sensitive to the green than to the blue portions of the spectrum. This result was so totally opposed to the generally received notions that the subject was submitted to further examination. In the next experiments a comparison was instituted between dry bromide plates and the same plates when wet from the bath solution of silver nitrate. The results showed a decided difference in the behaviour of the plates. The sensibility of dry bromide plates appears to extend to a greater extent into the least refrangible end of the spectrurn than is the case with wet plates. In Dr. Vogel's plates, in fact, which received the spectrum'formed by the battery of prisms of a direct vision spectroscope from a ray of sunlight reflected from a heliostat and passing through a slit $0.25 \mathrm{~mm}$. wide, the photographic impression of the spectrum, when developed by an acid developer, extended in the case of the dry plates into the orange, but with wet plates not quite into the yellow. The bromide plates prepared by Vogel, moreover, did not exhibit that increased sensitiveness for the green rays which characterised Col. Stuart Wortley's plates, and this led the German investigator to conjecture that the latter plates contained some substance which absorbed the green to a greater extent than the blue. To test this

\footnotetext{
* Poggendorff's Annalen, vol. cl., p. 453.
} 
conclusion one of the plates was washed in alcohol and water in order to remove the yellow colouring matter with which the plate was coated, and it was then found to have lost, in accordance with Dr. Vogel's anticipations, its sensitiveness for the green rays. The peculiar action of the Wortley dry plates was thus shown to be due to the coating of colouring matter, and the next step made by Vogel was to seek some substance which especially absorbed in the yellow, and at the same time acted as a sensitiser by fixing the free bromine liberated by the action of light upon the silver bromide. Both these ends are fulfilled by the coal-tar colour known as coralline. A plate dyed with this substance and exposed to the spectrum exhibited two maxima of photographic action, one the ordinary maximum in the indigo (near $\mathrm{G}$ ), and the other, almost as strong, in the yellow, thus affording complete confirmation of Dr. Vogel's views. Aniline green* was next tried. This dye is stated to absorb the red rays, and a corresponding increase of sensitiveness for the red rays was observed, the photograph again presenting two maxima of activity, the one in indigo and one in the red coinciding in position with the absorption band of the dye. Thus Dr. Vogel's results may be summarised by saying that a dyed film of silver bromide exhibits maxima of sensitiveness in those regions where the colouring matter exerts its maximum of absorptive power, but the precise conditions under which these results can be obtained must be considered at present as unknown, since many observers in repeating the experiments, among others Dr. Van Monckhoven, $\dagger$ have failed to obtain other than negative results.

In a communication made to the French Academy on the $27^{\text {th }}$ of last month, however, the well-known physicist, M. Edm. Becquerel, stated that some experiments made at his instigation by M. Deshaies at the Conservatoire des Arts ct Métiers had been productive of positive effects, and that some of Dr. Vogel's results with coralline and aniline green had been reproduced. M. Becquerel, however, does not confine himself to bromide films; similar results have been obtained by iodised collodion in which coralline was dissolved. A most remarkable action was observed also in the case of chlorophyll when this substance was used as a tinctorial agent. Although the collodion possessed only a faint green colour from the dissolved chlorophyll, the spectral image was of a much greater length than when plain collodion was used. Under these last circumstances the spectrum extended from the ultravinlet to between $\mathrm{G}$ and $\mathrm{F}$, with the usual maximum of action near $G$, while with chlorophyll the region of strongest action extended from the ultra-violet to the line $\mathrm{E}$ in the green, and at the same time a weaker but yet distinct impression extended from $\mathrm{E}$ to beyond $\mathrm{B}$ in the red, with a strong band between $C$ and $D$. By a close examination of the spectral image a second band of less intensity could be detected on the least refrangible side of the band between $C$ and $D$, and other still weaker bands appeared in the green. The most striking confirmation of Vogel's results is to be found in the fact, observed by $M$. Becquerel, that the band between $C$ and $D$ corresponds in position with the characteristic band of the absorption spectrum of chlorophyll dissolved in collodion.

* The green referred to is probably that known as "aldehyde green." The so-called "iodine green," as I have frequently observed, transmits a and in the red

t Photographic fournal, No. 25, June 20, 1874 .
The same results were obtained by $M$. Becquerel with every plate tried and with collodions containing different quantities of chlorophyll.

It must be admitted, then, that a film exerting selective absorption in intimate contact with a sensitive film of silver bromide or iodide affects the latter in those parts of the spectrum where the selective action is taking place. Here surely is a wide field for investigation, and one the importance of which will be at once obvious to the physicist. Practically also, when the precise conditions of action are made known, valuable results may be anticipated from the application of this principle to science and to art. Since the year $18+2$, when M. Becquerel photographed the whole solar spectrum from the extreme violet to the extreme red, and when Dr. J. W. Draper photographed the violet, blue, and extreme red, no successful attempts have been made to imprint the least refrangible end of the spectrum ; and this, when we consider the great importance that the study of the solar spectrum has assumed of late years and the painful or even dangerous character of prolonged eye observation, is to us a matter of wonder. M. Becquerel's result, it will be remembered, was obtained by a film of silver iodide, first insolated or exposed to diffused light and then to the action of the spectrum. Here again is another question-the precise action of insolation on sensitive plates-demanding explanation at the hands of the physicist. The practical aspect of Dr. Vogel's discovery need not here be discussed at length. Attention may be called to the well-known difficulty of getting reds or yellows to imprint themselves in portraiture, a difficulty which now bids fair to be overcome.

Then again, in what we must consider as a higher sphere of practical utility, great advantage to the study of solar physics is likely to accrue. In point of fact the photographic method of comparing spectra described in a recent communication to the Royal Society now becomes available for the whole extent of the solar spectrum, and our knowledge of the true composition of the sun will be thus in course of time recorded permanently on "that retina which never forgets."

Great results have already been achieved by photography, and greater may be looked for. It must not be forgotten that in this most interesting branch of chemical physics we are in a period either of provisional hypothesis, or, worse still, of no hypothesis at all, so that valuable additions to our knowledge of physical and chemical laws should be forthcoming. The changes wrought by a beam of light on sensitive surfaces are sometimes physical and sometimes chemical. We may appropriately recall here the fact that mechanical pressure upon a sensitised surface of a silver salt acts in the same manner as a ray of light, giving a dark stain under the action of reducing agents. The experiment of Grove also, in which an electric current is set up by the incidence of a beam of light upon a prepared Daguerreotype plate, should not be forgotten. The equivalence between light and the other form of force has not yet been established, and it may not be going too far to conjecture that thermodynamics may possibly in the future bave to appeal to the action of light upon a photographic plate. In the meantime we look forward to the promised continuation of Dr. Vogel's researches with no little hope.

R. MELDOLA 